
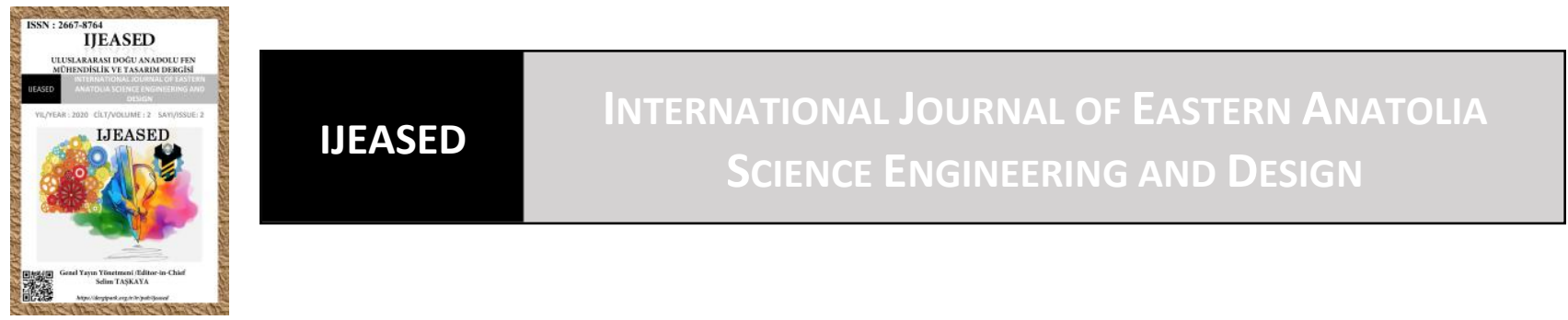

\author{
Uluslararası Doğu Anadolu Fen Mühendislik ve Tasarım Dergisi \\ ISSN: 2667-8764, 2(2), 308-324, 2020 \\ https://dergipark.org.tr/tr/pub/ijeased
}

Araştırma Makalesi / Research Article

Doi: $10.47898 /$ ijeased.800037

\title{
Alan Kullanımı/Arazi Örtüsü Değişiminin Mekansal ve Zamansal Analizi: İzmir/Türkiye Örneği
}

\author{
İpek KARAALí ${ }^{1 a^{*}}$, Ebru ERSOY TONYALOĞLU ${ }^{2 a}$, Birsen KESGIN ATAK ${ }^{2 b}$, Engin NURLU ${ }^{1 b}$
}

${ }^{1}$ Ege Üniversitesi, Ziraat Fakültesi, Peyzaj Mimarlığı Bölümü, İzmir, 35030, Türkiye.

${ }^{2}$ Aydın Adnan Menderes Üniversitesi, Ziraat Fakültesi, Peyzaj Mimarlığı Bölümü, Aydın, 09100, Türkiye.

\begin{tabular}{|c|c|c|}
\hline Yazar Kimliği / Author ID (ORCID Number) & \multicolumn{2}{|c|}{ Makale Süreci / Article Process } \\
\hline Sorumlu Yazar / Corresponding author: & Geliș Tarihi / Received Date : & 25.09 .2020 \\
\hline ipekkaraali23@gmail.com & Revizyon Tarihi / Revision Date : & 10.10 .2020 \\
\hline (iD) https://orcid.org/0000-0002-2125-8487, İ. Karaali & Kabul Tarihi / Accepted Date : & 24.10.2020 \\
\hline (iD) https://orcid.org/0000-0002-2945-3885 , E. Ersoy Tonyaloğlu & Yayım Tarihi / Published Date : & 15.12 .2020 \\
\hline (iD) https://orcid.org/0000-0003-4786-0801 , B. Kesgin Atak & & \\
\hline (iD https://orcid.org/0000-0001-5458-7749, E. Nurlu & & \\
\hline
\end{tabular}

Alıntı /Cite : Karaali, İ., Ersoy Tonyaloğlu, E., Kesgin Atak, B., Nurlu, E. (2020). Alan Kullanımı/Arazi Örtüsü Değişiminin Mekansal ve Zamansal Analizi: İzmir/Türkiye Örneği, Uluslararası Doğu Anadolu Fen Mühendislik ve Tasarım Dergisi, 2(2), 308-324.

\section{Özet}

Çalışmanın amacı 1990 ve 2019 yılları arasında nüfus artışı ile birlikte hızlı kentleşmenin yaşandığı İzmir ili Karşıyaka, Bayraklı, Konak ve Bornova ilçelerinde alan kullanım/arazi örtüsü (AK/AÖ)'nde meydana gelen değişimlerin peyzaj metrikleri ile analiz edilmesidir. Çalışmada 1990 yılına ait Landsat 4-5 TM ve 2019 yılına ait Landsat 8 uydu görüntüleri nesne tabanlı sınıflandırma yöntemi kullanılarak sınıflandırılmış ve 1990 ve 2019 yıllarına ait AK/AÖ haritaları elde edilmiştir. AK/AÖ değişimi, FRAGSTATS yazılımında sınıf düzeyinde 9 peyzaj metriğinden yararlanılarak yorumlanmıştır. Elde edilen sonuçlara göre, çalışma alanında en büyük değişim yapay yüzeylerde artış şeklinde yaşanmıştır. Yapay yüzeylerde baskın olarak sanayi ve yerleşim alanlarının hızla artması, doğal peyzajın bütünlüğünü bozarak çalışma alanında mevcut doğal peyzaj öğelerinde parçalanma, delinme ve izolasyona neden olmuştur.

Anahtar Kelimeler: Uzaktan algılama, Peyzaj metrikleri, Landsat uydu görüntüleri, Alan kullanım/arazi örtüsü, Nesne tabanlı siniflandirma. 


\title{
Analysis of Spatio-temporal Land Use/Land Cover Change: Case of Izmir, Turkey
}

\begin{abstract}
This study aims to analyze the changes in land use/land cover (LU/LC) using landscape metrics in Karşlyaka, Bayrakll, Konak and Bornova districts of Izmir metropolitan city, where the rapid urbanization was experienced together with population growth between 1990 and 2019. LU/LC maps were derived from Landsat 4-5 TM and Landsat 8 satellite images of 1990 and 2019 using object-based classification method. LU/LC change has been detected and interpreted in FRAGSTATS software using 9 core landscape metrics at class level. According to our results, the largest change in LU/LC was the increase in artificial surfaces. The rapid increase in industrial and residential areas of artificial surfaces disrupted the integrity of the natural landscape and caused fragmentation, perforation and isolation in the natural landscape elements in the study area.
\end{abstract}

Keywords: Remote sensing, Landscape metrics, Landsat satellite images, Land use/land cover, Object based classification.

\section{Giriş}

Peyzaj ekolojisi, peyzaj yapısı, süreçler (işlev) ve değişim arasındaki etkileşimin önemini vurgulamaktadır (Urban ve ark., 1987; Turner, 1989; Turner ve ark., 2001). Peyzaj yapıs1, peyzajın doğal ve çok önemli bir yönünü ifade etmektedir ve bu nedenle peyzaj ekolojisi alanında birçok çalışma peyzaj yapısını analiz ederek bir peyzajın yapı, işlev(ler) ve değişim(ler)i arasındaki ilişkinin değerlendirilmesi üzerine temellendirilmiştir (Herold ve ark., 2002; Matsushita ve ark., 2006; DiBari, 2007; Yu ve Nakagoshi, 2007). Peyzajlar, zaman ve mekan içinde mekansal bileşenlerin kompozisyonundan oluşturmaktadır. Peyzajların mekansal yapısının belirlenmesi peyzaj ekolojisi araştırmalarının ana amaçlarından birini oluşturmaktadır. Peyzaj yapısı, hem doğal çevrenin hem de insan kaynaklı değişimlerin karmaşık koşullarını ifade etmektedir. Peyzaj, doğal ve kültürel süreçlerin birbiri ile etkileşimi sonucunda değişime uğrayan dinamik bir yapıya sahiptir. Tüm canlılarla birlikte insanlar da meydana gelen değişimlerden etkilenmektedir. Bu değişimler zaman zaman fark edilemeyecek boyutta ilerleyip, sonuçta peyzaj üzerinde ciddi boyutta etkilere yol açmaktadır. Peyzajda meydana gelen değişimler, doğal süksesyonların dışında, sanayileşme, kentleşme, tarım faaliyetleri gibi insan faaliyetlerinden kaynaklanan gelişmeler ile oluşabilmektedir. Sürdürülebilir gelişmeye engel olan ve insan yaşamını doğrudan etkileyen bu değişimlerin izlenmesinde ve gerekli tedbirlerin alınmasında biyolojik çeşitlilik, kentleşme, alan kullanım/arazi örtüsü (AK/AÖ) ve nüfus değişimi gibi göstergeler kullanılmaktadır (OECD, 2003; U.S. EPA, 2008; Nurlu ve ark., 2008 ve 2009).

AK/AÖ haritaları, peyzaj yapısının incelenmesinde sıklıkla kullanılan ve peyzajdaki kategorik coğrafi birimlerin mekansal olarak gösterimini yansıtan en önemli peyzaj göstergelerinden birini oluşturmaktadır. Alan Kullanımı (AK), insanlığın arazi örtüsünden ne şekilde yararlandığını ifade 
etmekte ve arazi yönetim uygulamalarını içermekteyken, Arazi Örtüsü (AÖ) kavramı ise arazinin yüzeyini kaplayan doğal bitki örtüsünü, toprak tabakası ile biyomasını, tarım ürünlerini ve diğer tüm insan yapılarını ifade etmektedir (Verburg ve ark., 2009; Somuncu ve ark., 2010). Tanımlardan da anlaşıldığı gibi, AÖ kavramı genellikle, çevresel koşullara bağlı olarak şekillenmekteyken, AK kavramı ise insanların farklı ihtiyaçlarının karşılanması amacıyla çeşitli sosyo-ekonomik ve sosyokültürel bileşenler doğrultusunda, insan ve çevre arasında bir ilişki kurmaktadır. Dolayısıyla, AK ve AÖ'nde yaşanan değişimler genellikle birbirlerini etkilemekte, çoğu zaman birbirinde yaşanan değişimleri tetiklemektedirler. AK/AÖ değişimi, günümüzde küresel ölçekte doğal ve sosyal sistemler ile bağlantılı olan karmaşık ve biyoçeşitlilik, yerel / bölgesel / küresel iklim ile ekosistem servisleri vb dinamik süreçler üzerinde etkili olmaktadır (Turner ve ark., 1990). Bu kapsamda, AK/AÖ belirlenmesi ve zaman içindeki değişiminin izlenmesi, peyzaj planlama ve yönetiminde karar vericilere yardımcı olmakta ve mevcut değişimler üzerinden eğilimlerin saptanması yoluyla yanlış kararların belirlenmesi ve gelecekte daha sağlıklı planlama kararlarının alınmasında önemli bir rol oynamaktadır. AK/AÖ değişiminin belirlenebilmesi ancak düzenli aralıklarla tutulmuş zamansal veriler ile mümkün olmaktadır. $\mathrm{Bu}$ kapsamda, mevcut peyzajların doğal ve kültürel özellikleri temelinde bir dizi tematik kategoriye ayrılması süreci olan AK/AÖ haritalaması, peyzajların mevcut ve geçmiş durumu hakkında bizlere 1şı tutmaktadır.

Peyzajdaki değişimleri incelemek için yaygın olarak kullanılan göstergelerden biri olan arazi örtüsü (AÖ) göstergeleri, genellikle uydu görüntülerinden oluşan veri setleri kullanılarak, yarı doğal ve doğal alanlardaki kayıpları ve kazançları, belirlenen arazi örtüsü (AÖ) sınıflarındaki değişimi ve dönüşümü, yapay yüzeylerdeki gelişimi (kentsel alanlar, sanayi ve maden alanları gibi yapay yüzeylerin değişimi) ve yüzey sularındaki değişimi izlemek için kullanılmaktadır (OECD, 2017; Haščič ve Mackie, 2018; Ersoy, 2019). Peyzajda geleceğe yönelik vizyon oluşturulması, uygulanan plan kararlarının doğruluğuna, peyzajın yönetilmesine ve bunların sonucunda oluşan peyzaj değişimlerine bağlıdır (U.S. EPA, 2008; Nurlu ve ark., 2008 ve 2009). AK/AÖ değişimleri peyzajın değişimini ortaya koyan önemli göstergelerdendir (U.S. EPA, 2008). Bu kapsamda, uzaktan algılama (UA) teknikleri ve coğrafi bilgi sistemlerinin (CBS) kullanımı ile AK/AÖ değişimleri saptanabilmektedir (Bürgi ve ark., 2004). Peyzajların ileriye yönelik gelişme eğilimlerini de göstermesi açısından, AK/AÖ’deki değişimler oldukça önemlidir. Peyzajlarda oluşan değişimleri olumlu yönde etkilemek, doğru ve etkili plan kararları ve bu plan kararlarının olası sonuçlarına karşı gerçekçi öngörülerle mümkün kılınabilmektedir (Barredo ve ark., 2003a ve 2003b). Bu kapsamda, tüm dünyada ve Türkiye'de AK/AÖ değişimleri analiz edilerek değerlendirilmektedir. 
Örneğin, Alphan (2003)'ın kent ve kent bitişiğindeki tarım alanları ve yarı doğal alanlar üzerinde durduğu çalışmada, Adana ilinde 1984 ve 2000 yılları arasında meydana gelen değişimler incelenmiş ve meydana gelen değişimlerde göçler ve kalkınma stratejilerinin etkili olduğu belirtilmiştir. Kesgin ve Nurlu (2009) sınıflandırma sonrası karşılaştırma yöntemi kullanarak İzmir ili Çandarlı ilçesinde peyzajda meydana gelen değişimleri tespit etmişlerdir. Herold ve ark (2002) 1978-1998 yılları arasında California, USA’de kentsel büyümeden kaynaklanan AK/AÖ değişimini peyzaj metrikleri ile analiz etmiştir. Ji ve ark (2006) ise Landsat uydu görüntülerinin yardımı ile 1972-2001 yılları arasında Kansas, USA'de kentsel büyümeyi peyzaj metriklerini kullanarak karakterize etmiştir. Bunlara ek olarak, Kesgin Atak ve Ersoy Tonyaloğlu (2019) 1990 ve 2017 yıllarına ait Landsat uydu görüntülerini kullanarak Aydın ilinde NDVI verilerine dayanan yöntem kullanılarak, yoğun kentleşme bölgelerindeki AK/AÖ değişimlerine bağlı karasal karbon depolarının potansiyelleri incelenmiştir.

Günümüzde peyzaj yapısını analiz etmek, değerlendirmek ve peyzajda meydana gelen değişimleri tespit etmek için geliştirilmiş çeşitli yöntemler ve araçlar bulunmaktadır. Peyzajda meydana gelen değişimlerin tespit edilmesinde kullanılan yöntemlerden birisi de farklı yazılımlar $\operatorname{aracılığı~ile~peyzaj~metriklerinin~hesaplanmasıdır.~Peyzaj~metrikleri,~peyzaj~planlama~çalışmalarına~}$ 1şık tutan birçok mekansal ve mekansal olmayan verinin elde edilmesine yardımcı olmakta ve peyzaj yapısının değerlendirilmesi, peyzaj işleyişi (fonksiyonları) ile değişiminin analiz edilmesi ve saptanmasında temel olabilecek birçok veri sağlamaktadır. Özellikle, peyzaj yapısı ile fonksiyonu ve değişimi arasında belirgin ilişkiler elde edilebildiğinde, peyzaj metrikleri peyzaj plancıları için çok önemli araçlar olarak karşımıza çıkmaktadır. Peyzaj metrikleri, başta peyzajda yaşanan ekolojik işleyiş ve süreçler olmak üzere, farklı planlama modellerinin değerlendirilmesi ve karşılaştırılması ile bu modellerin mevcut peyzaj sistemi üzerindeki olas1 etkilerinin saptanmas1 ve değerlendirilmesinde de etkin bir şekilde kullanılmaktadır (Martensen ve ark., 2008; Deng ve ark., 2009; Aguilera ve ark., 2011). Peyzaj metrikleri, özellikle niceliksel (sayısal) bilgilerin üretilmesi yoluyla, planlamada objektif kararlar alınmasına da yardımcı olmaktadır.

Peyzaj değişim süreçlerinin daha iyi anlaşılması amacıyla da kullanılan peyzaj metrikleri, genellikle 3 düzeyde hesaplanmaktadır. Bunlar; peyzaj mozaiği (tüm peyzaj), peyzaj sınıfları ve peyzaj lekeleri düzeylerinde hesaplanan farklı metriklerden oluşmaktadır. 3 farklı düzeyde hesaplanabilen peyzaj metrikleri, peyzajın kompozisyonu ve konfigürasyonu ile ilgili sayısal bilgiler elde etmemizi sağlayan önemli göstergelerdendir (Botequilha Leitão ve ark., 2006). Peyzaj kompozisyon metrikleri, peyzajın mekansal olmayan özellikleri hakkında, peyzaj konfigürasyon 
metrikleri ise mekansal özellikleri hakkında veri sağlamaktadır (Gustafson, 1998). Peyzaj metrikleri, birçok CBS ve UA yazılımının uzantısında (extension), örneğin Patch Analyst, hesaplanabileceği gibi, FRAGSTATS gibi bağımsız yazılımlar ile de hesaplanabilmektedir.

Çalışmanın amacı, 1990 ve 2019 yılları arasında 29 yıllık dönemde nüfus artışı ile birlikte hızlı kentleşmenin yaşandığı İzmir ili Karşıyaka, Bayraklı, Konak ve Bornova ilçelerinde AK/AÖ'nde meydana gelen değişimlerin peyzaj metrikleri ile analiz edilmesidir. Çalışmada, 1990 y1lı Landsat 4-5 TM uydu görüntüsü ve 2019 y1lı Landsat 8 uydu görüntüsüne nesne tabanlı sınıflandırma yöntemi uygulanarak, 1990 ve 2019 yıllarına ait AK/AÖ haritaları elde edilmiştir. Elde edilen AK/AÖ haritalarının değişim analizleri yapılmıştır. AK/AÖ değişimi, sınıf düzeyinde 9 peyzaj metriğinden yararlanılarak yorumlanmıştır.

\section{Materyal ve Metot}

\subsection{Materyal}

Çalışma alanı, İzmir ilinin Konak, Bornova, Bayraklı ve Karşıyaka ilçelerinin bir bölümünü (yaklaşık 22.193,5 ha alan) kaplamaktadır (Şekil 1).

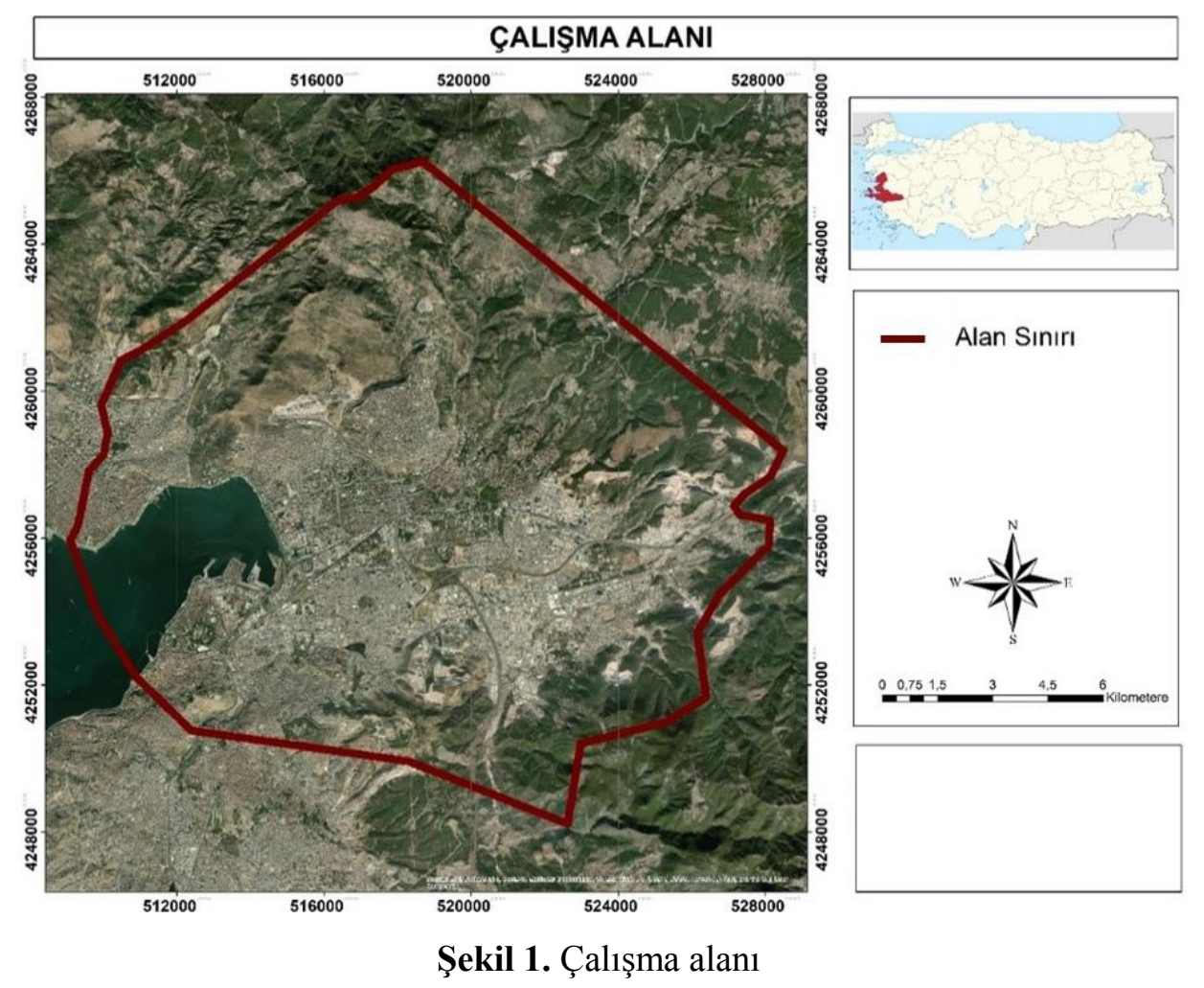


Türkiye'nin üçüncü büyük kenti olan İzmir kenti, Ege Bölgesi'nin bir kıyı kentidir. İlin, kuzeyinde Balıkesir, güneyinde Aydın, batısında ise Manisa illeri ile doğusunda Ege Denizi yer almaktadır. İzmir ili sınırları $37^{\circ} 45^{\prime}$ ve $39^{\circ} 15^{\prime}$ kuzey enlemleri ile $26^{\circ} 15^{\prime}$ ve $28^{\circ} 20^{\prime}$ doğu boylamları arasında yer almakta olup, ilin yüzölçümü 12.012 km²dir. İzmir'de bulunan Gediz Nehri ve Menderes Nehri, Ege Bölgesi’nin önemli akarsularıdır. İzmir kent merkezi, İzmir Körfezi’nin etrafına kurulmuştur. İzmir kıyı bandı, kuzeyde Dikili ilçesine, güneyde Selçuk ilçesine kadar uzanmaktadır. Bu özellikleriyle İzmir, doğal bir turizm ve liman kentidir (İÇDR, 2019). İzmir'de yazları sıcak ve kurak, kışları 1lık ve yağışlı olmak üzere tipik Akdeniz iklimi görülmektedir. Dağların denize dik olması ve ovaların İç Batı Anadolu’ya kadar uzanması, karasal ortamda denizel iklimin yaşanmasına olanak sağlamaktadır. En sıcak aylar Temmuz-Ağustos, en soğuk aylar Ocak ve Şubat aylarıdır. İlde kar yağışı yok denecek kadar azdır (İÇDR, 2019). İzmir ilinin topraklarının büyük bir bölümü, kırmızı Akdeniz toprakları ve kalkersiz kahverengi topraklardır. Akdeniz'in doğal bitki örtüsünün özelliklerini gösteren İzmir ilinde, geniş, sert ve iğne yapraklı, sürekli yeşil kalan, kuraklığa dayanıklı ağaç ve çalılar doğal bitki örtüsünü oluşturmaktadır. İzmir ilinin nüfusu 2019 TUİK verilerine göre 4.367.251 kişidir. Bu sayı ile İzmir ili, Türkiye’nin en büyük üçüncü büyük şehridir (TUİK, 2019).

Çalışmada veri kaynağı olarak, Landsat 4-5 TM ve Landsat 8 uydu görüntüleri kullanılmıştır. Landsat 4-5 TM uydu görüntüsünün Blue (Band1), Green (Band2), Red (Band3), NIR (Band4), SWIR (Band5), SWIR (Band7,) bandları olmak üzere 6 spektral bandı kullanılmıştır. Landsat 8 uydu görüntüsünün ise, Coastal (Band1), Blue (Band2), Green (Band3), Red (Band4), NIR (Band5), SWIR (Band6), SWIR (Band7) bandları olmak üzere 7 spektral bandı kullanılmıştır (Şekil 2). 


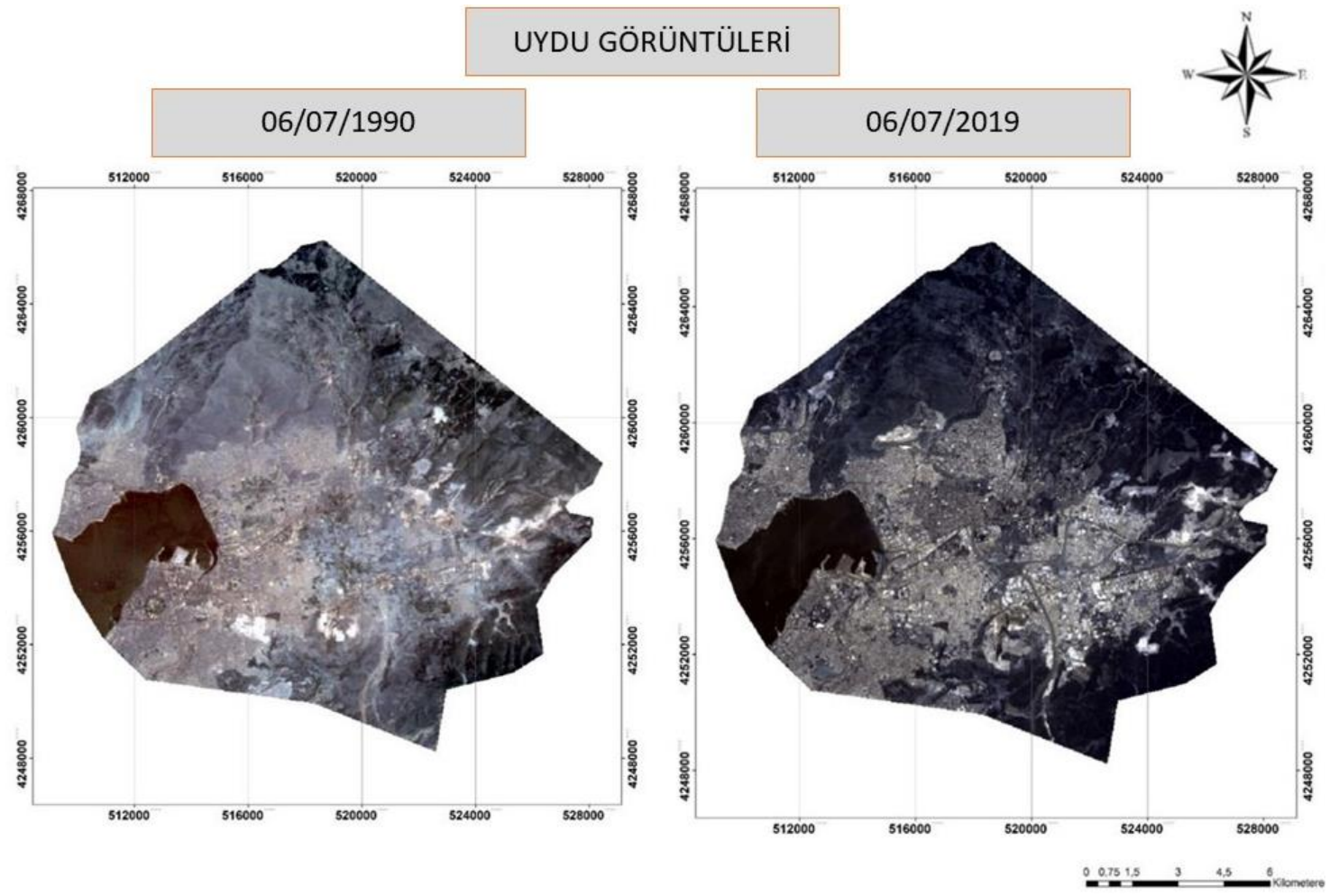

Şekil 2. 1990 ve 2019 yıllarına ait Landsat uydu görüntüleri

Çalışmada, ASTER Küresel Sayısal Yükseklik Modeli (SYM) yardımcı veri olarak kullanılmıştır. ASTER verileri, karasal yüzeylerin sıcaklığı, yansıma değerleri ve yükseklik verileri hakkında ayrıntılı haritalar yapmak için kullanılmaktadır (ASTER, 2016). Bu çalışmada SYM verisi, AK/AÖ haritalarını oluşturmada nesne tabanlı sınıflandırma yöntemi kullanılarak yapılan segmentasyon işlemi için kullanılmıştır (Şekil 3). 


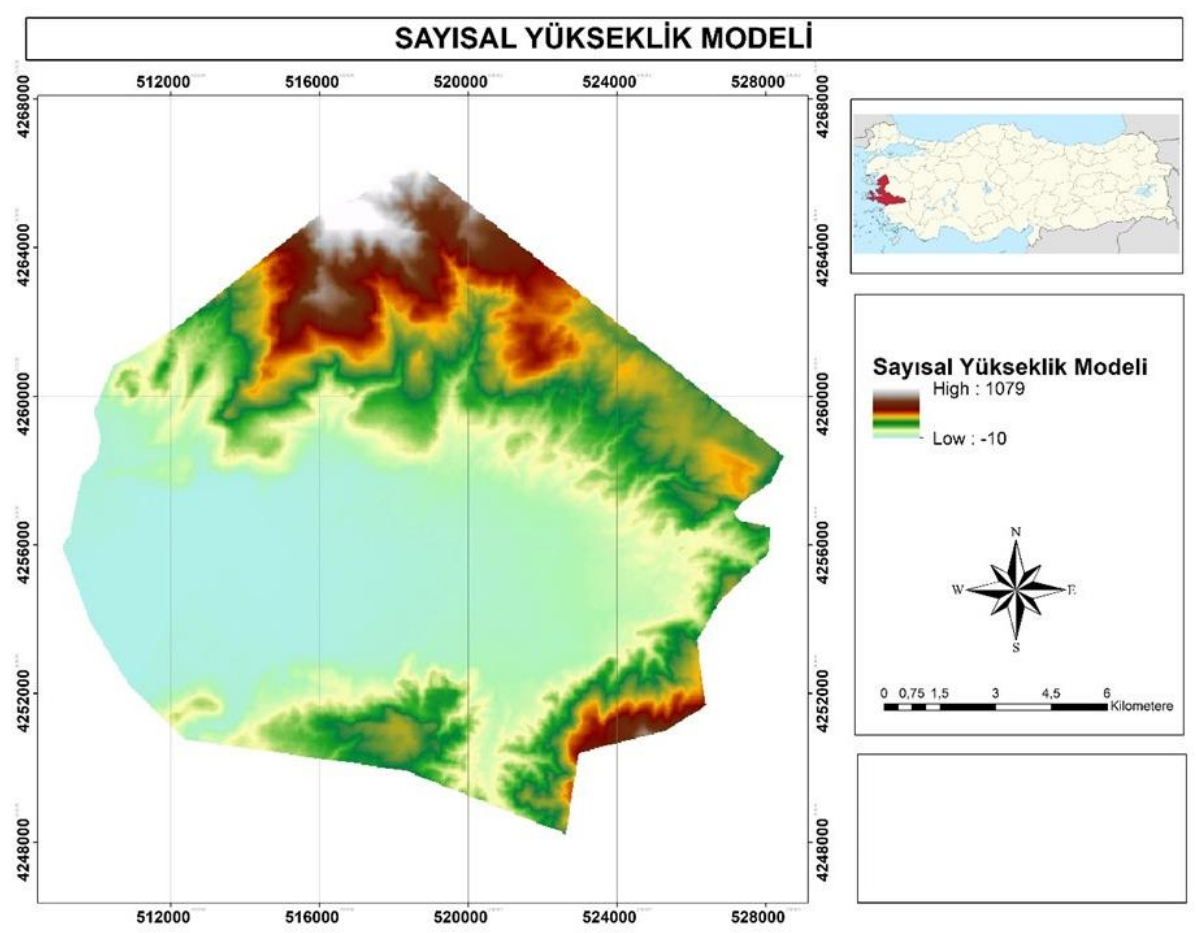

Şekil 3. Çalışma alanına ait SYM (DEM) verisi

AK/AÖ sınıflandırma çalışmalarında, nesne tabanlı sınıflandırma yöntemi uygulanmıştır. Bu kapsamda uydu görüntülerinin sınıflandırılmasında eCognition Developer 9.1 (Trimble Geospatial, 2015) ve ArcGIS 10.7 (ESRI, 2019) yazılımları kullanılmıştır. Sınıflandırmada, eCognition Developer 9.1 yazılımı, En Yakın Komşuluk Yöntemi (Nearest Neighbor) kontrollü sınıflandırma yönteminden yararlanılmıştır. AK/AÖ meydana gelen değişimlerin tespit edilmesinde, ENVI 5.1 (L3Harris Geospatial, 2013) ve FRAGSTATS 4.2.1 (McGarigal ve ark., 2012) yaz1lımları kullanılmıştır. 1990 ve 2019 yılları arasındaki değişimin saptanmasında ENVI 5.1 yazılımı, peyzaj yapısındaki değişimlerin saptanmasında FRAGSTATS 4.2.1 yazılımı kullanılmıştır.

\subsection{Yöntem}

Çalışmanın yöntemi, 1990 ve 2019 yıllarına ait Landsat uydu görüntülerinin nesne tabanlı sınıflandırma yöntemi ile sınıflandırılması ve AK/AÖ haritalarının oluşturulması, oluşturulan AK/AÖ haritalarının değişimlerinin belirlenmesi ve peyzaj metriklerinden faydalanarak değişim analizinin yapılması aşamalarından oluşmaktadır (Şekil 4). 


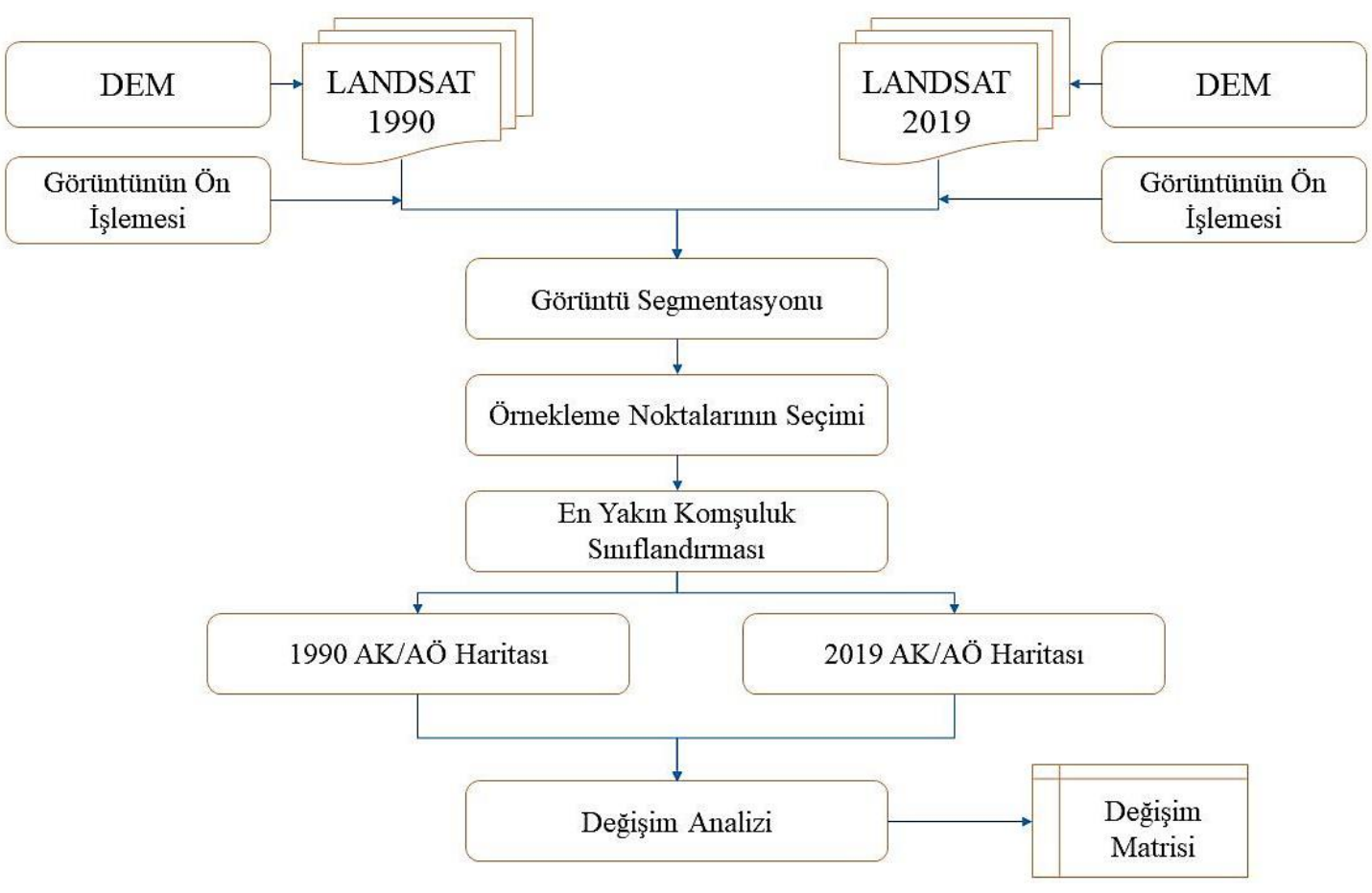

Şekil 4. Yöntem akışşseması

Çalışma alanının 1990 yılına ait 30 m yer çözünürlüğünde Landsat 4-5 TM uydu görüntüsü ve 2019 yılına ait 30 m yer çözünürlügünde Landsat 8 uydu görüntüleri nesne tabanlı sınıflandırma yöntemi ile sınıflandırılmıştır. Nesne tabanlı sınıflandırma yönteminde, ilk aşamada uygun parametreler ile segmentasyon işlemi gerçekleştirilmiştir. Segmentasyon aşamasında 1990 yılı Landsat 4-5 uydu görüntüsü ve 2019 yılı Landsat 8 uydu görüntüsünün bandlarına ek olarak, ASTER Küresel SYM verisi yardımcı veri olarak kullanılmıştır. Bandların yansıma değerleri ile çözünürlükleri göz önünde bulundurularak, en uygun parametreler belirlenmiştir. Segmentlere ayrılan uydu görüntülerinin sınıflandırma işleminde AK/AÖ sınıfları belirlenmiş ve belirlenen AK/AÖ sınıflarına uygun örnek seçimleri yapılmıştır. Çalışma alanının sınıflandırılmasına yönelik, alanın kullanım durumuna uygun alt sınıflar oluşturulmuştur. Landsat 4-5 uydu görüntüsü ile Landsat 8 uydu görüntüsü için 24 alt sınıf oluşturulmuştur. Oluşturulan alt sınıflar, yapay yüzeyler (kentsel alanlar, sanayi alanları, maden ve depolama alanları vb. gibi), tarım alanları, orman alanları, maki ve otsu bitkiler, bitki örtüsü az/hiç olmayan alanlar, su yüzeyleri ve kent içi yeşil alanlar olmak üzere 7 ana sınıfta toplanmıştır.

Sınıflandırmaların doğruluğunu ve geçerliliğini ölçmek amacıyla, sınıflandırma sonunda elde edilen elde edilen AK/AÖ haritalarına doğruluk analizi uygulanmıştır. 1990 ve 2019 yıllarına ait sınıflandırılmış uydu görüntülerinin doğruluklarının belirlenmesinde, hata matrisi ve Kappa (k) 
katsayısı ile doğruluk analizi uygulanmıştır (Foody, 2002; Congalton ve Green, 1999). Toplam doğruluk, üretici doğruluğu, kullanıcı doğruluğu ve Kappa istatistik değerleri hesaplanmıştır. Landsat 4-5 ve Landsat 8 uydu görüntüleri kullanılarak elde edilen AK/AÖ haritalarının doğruluk analizleri, ArcGIS 10.7 yazılımında gerçekleştirilmiştir (Şekil 4).

Son olarak FRAGSTATS 4.2.1 yazılımı yardımıyla sınıf düzeyindeki peyzaj metriklerinden toplam yama alanı (CA), peyzaj yüzdesi (PLAND), parça/yama sayısı (NP), ortalama alan (AREA_MN), alan ağırlıklı ortalama alan (AREA_AM), Öklid en yakın komşu mesafesi (ENN_AM), yakınlık indeksi (PROX_AM), etkin ağ büyüklüğü (MESH) ve bitişiklik indeksi (IJI) hesaplanmıştır (Tablo 1).

Tablo 1. Araştırmada kullanılan peyzaj metrikleri (Leitão ve ark., 2012; McGarigal, 2014)

\begin{tabular}{|c|c|c|c|c|}
\hline Metrik Adı (İng) & Metrik Ad 1 (TR) & Birim & Kisaltma & Kullanım Amacı \\
\hline Total Areaa & Toplam yama alanı & ha & $\mathrm{CA}$ & Baskınlık, hakimiyet \\
\hline Percentage of Landscape & Peyzaj Yüzdesi & $\%$ & PLAND & Baskınlık, hakimiyet \\
\hline Number of Patches & Parça/yama sayısı & & NP & Parçalanma \\
\hline Patch Area Mean & Ortalama alan & ha & AREA-MN & NP ile birlikte parçalanma \\
\hline $\begin{array}{l}\text { Euclidean Nearest Neighbor } \\
\text { Distance }\end{array}$ & $\begin{array}{l}\text { Öklid en yakın komşu } \\
\text { mesafesi }\end{array}$ & $\mathrm{m}$ & ENN-AM & Parçalanma ve izolasyon \\
\hline Proxymitiy Index & Yakınlık indeksi & & PROX-AM & Parçalanma/Bağlantılılık \\
\hline Effective Mesh Size & Etkin ağ büyüklüğü & & MESH & Parçalanma/Bağlantılılık \\
\hline $\begin{array}{l}\text { Patch Area- Area Weighted } \\
\text { Mean }\end{array}$ & $\begin{array}{l}\text { Alan ağırlıklı ortalama } \\
\text { leke büyüklüğü }\end{array}$ & ha & AREA-AM & NP ile birlikte parçalanma \\
\hline $\begin{array}{l}\text { Interpersion Juxtaposition } \\
\text { Index }\end{array}$ & Bitişiklik indeksi & & IJI & Parçalanma/Bağlantılılık \\
\hline
\end{tabular}

\section{Bulgular ve Tartışma}

Sınıflandırma sonrası AK/AÖ haritalarının doğruluk analizleri sonucunda 1990 yılı AK/AÖ için kullanıcı doğruluğu \%91, Kappa değeri \%89 iken 2019 AK/AÖ için kullanıcı doğruluğu \%98, Kappa değeri \%98 olarak hesaplanmıştır. 1990 ve 2019 yıllarına ait AK/AÖ haritaları Şekil 5'te verilmiştir. 


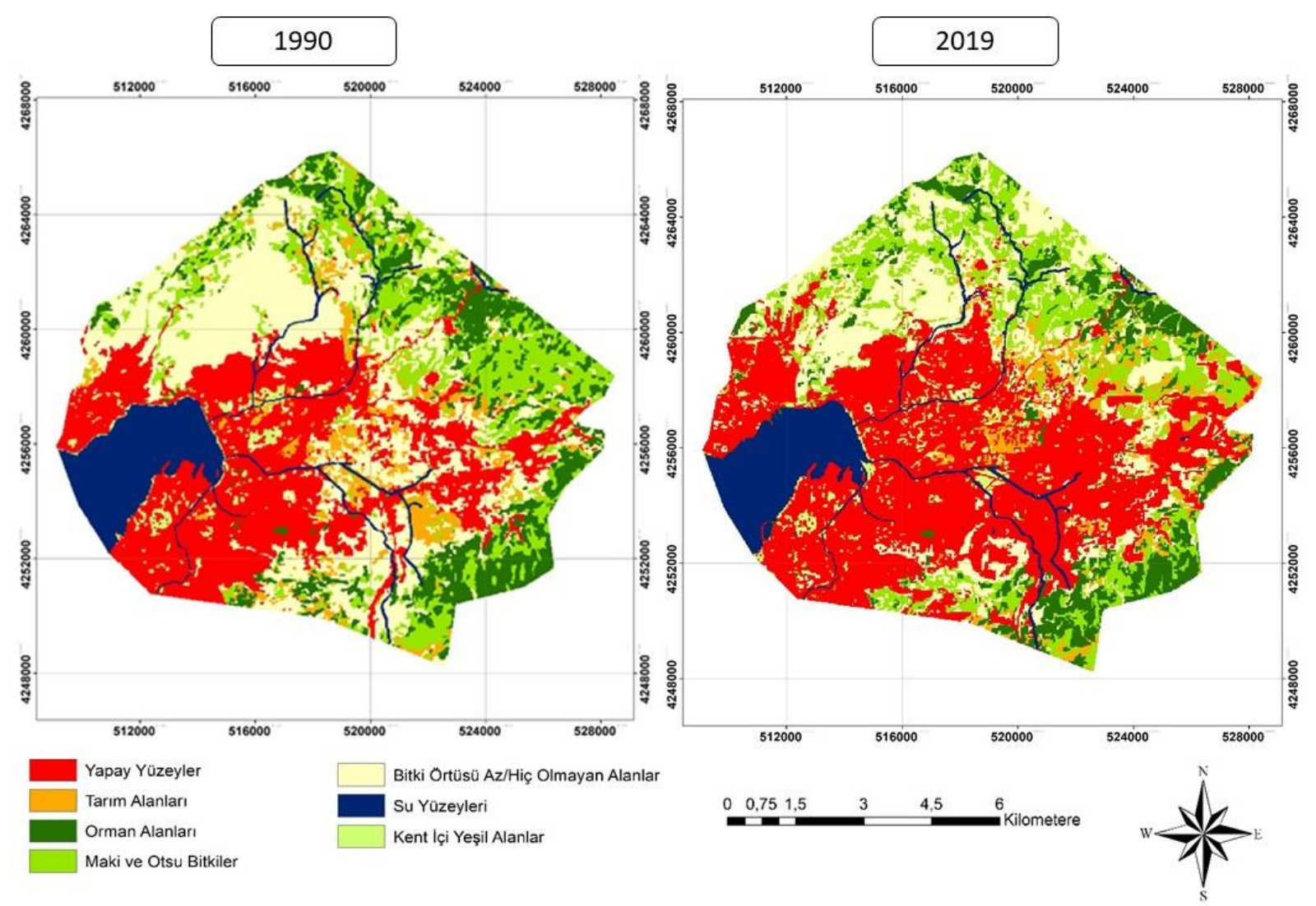

Şekil 5. 1990 ve 2019 y1lları AK/AÖ haritaları

1990 ve 2019 yıllarına ait AK/AÖ haritalarındaki farklı AK/AÖ sınıflarının toplam alanları Tablo 2'de sunulmuştur. Elde edilen veriler incelendiğinde, 1990 ve 2019 yılları arasında en büyük değişim \%12,4 olarak yapay yüzeyler sınıfında meydana geldiği görülmektedir. Bu değişimi \%9,1'lik değişim ile bitki örtüsü az/hiç olmayan alanlar izlemiştir. Tarım alanları \%1,21, orman alanları \%2,9, su yüzeyleri \%0,25 oranında azalırken, kent içi yeşil alanlar \%1 artış göstermiştir. En az değişime uğrayan sınıf ise \%0,03 ile maki ve otsu bitkiler sınıfı olmuştur (Tablo 2).

Tablo 2. 1990 ve 2019 y1llarına ait AK/AÖ sınıfları ve alanları (ha)

\begin{tabular}{lllc}
\hline AK/AÖ Sınıfları & 1990 (ha) & 2019 (ha) & \% Değişim \\
\hline Yapay Yüzeyler & 6148,08 & 8915,49 & 12,4 \\
Tarım Alanları & 1420,02 & 1150,11 & 1,21 \\
Orman Alanları & 2709,9 & 2066,31 & 2,9 \\
Maki ve Otsu Bitkiler & 3292,38 & 3288,87 & 0,03 \\
Bitki Örtüsü Az/Hiç Olmayan Alanlar & 6336,81 & 4320,27 & 9,1 \\
Su Yüzeyleri & 1930,14 & 1873,62 & 0,25 \\
Kent İçi Yeşil Alanlar & 356,13 & 578,79 & 1 \\
Toplam & 22193,5 & 22193,5 & - \\
\hline
\end{tabular}


1990 ve 2019 yılları arasındaki 29 yıllık dönemde, çalışma alanında yaşanan değişimleri tespit etmek ve bu değişimin yarattığı, neden olduğu yapısal ve işlevsel süreçleri açıklamak amacıyla hesaplanan 9 peyzaj metriğine ilişkin sonuçlar Tablo 3'te verilmiştir. Her iki yılda da çalışma alanında baskın AK/AÖ sınıfının yapay yüzeyler olduğu tespit edilmiştir. Yapay yüzeyler, kent merkezinin genişlemesi ve buna bağlı olarak yapılaşmanın artması sonucunda 29 yıllık dönem sonunda 2.767,4 ha artmıştır. Bu durum maki, orman ve tarım alanlarını parçalamış ve daraltmıştır. Her ne kadar maki ve otsu bitkiler sınıfının toplam alanında ciddi bir azalma olmamış olsa da artan NP, azalan AREA_MN ve AREA_AM değerleri, PROX_AM ve ENN_AM değerleri ile birlikte ele alındığında, maki ve otsu bitkiler sınıfında artan parçalanma ve izolasyona işaret etmektedir. Diğer yandan orman alanları sınıfının toplam alanı yaklaşık \%25 azalma göstermiştir. Artan NP, azalan AREA_MN ve AREA_AM değerleri, PROX_AM, ENN_AM ve MESH değerleri ile birlikte orman sınıfında çok ciddi parçalanmaların meydana geldiğini ve fiziksel/mekansal bağlantılılığın zayıfladığı anlamını taşımaktadır. 29 yıllık dönem içinde tarım alanlarında da benzer bir değişim meydana gelmiştir. Yapılaşma faaliyetleri doğal peyzajda bölünme ve delinmelere yol açmıştır. Kentsel bölgelerin gelişmesi tarımsal faaliyetlerde de azalmayı beraberinde getirmiş, kentsel gelişme tarım alanları üzerinde baskı oluşturmaya başlamıştır. 1990-2019 yılları arasında tarım alanlarında 269,91 ha alan kaybı meydana gelmiştir.

1990-2019 yılları arasında bitki örtüsü az/hiç olmayan alanlardan 2.018,61 ha kadar kayıp olmuştur. Bitki örtüsü az/hiç olmayan alanlarda yaşanan kayıplar yapay yüzeylere, tarım alanları ve az da olsa orman alanlarına dönüşüm şeklinde yaşanmıştır. Diğer yandan ormanlarda 650,16 ha alan kaybı yaşanmıştır. Artan NP, azalan AREA_MN ve AREA_AM değerleri orman alanlarına artan parçalanma ve delinme süreçlerine işaret etmektedir. Son 19 yıllık süre zarfında orman alanlarında yaşanan parçalanma ve delinmeler aynı zamanda orman peyzajı bağlantılılığını olumsuz yönde etkileyen faktörler arasında yer almaktadır. Kent içi yeşil alanlarda 222,6 ha alan artış1 görülmektedir. 1990-2019 yılları arasında alanlarda sırasıyla; bitki örtüsü az/hiç olmayan alanlarında 2.016,54 ha, orman alanları 643,59 ha, tarım alanlarında 269,91 ha, su yüzeylerinde 56,52 ha, maki alanlarında 3,51 ha kayıplar görülmüştür. Aynı dönemde yapay yüzeyler 2.767,41 ha, kent içi yeşil alanlar ise 222,6 ha artmıştır. 
Tablo 3. 1990 ve 2019 yıllarına ait peyzaj metrikleri sonuçları

\begin{tabular}{|c|c|c|c|c|c|c|c|c|c|c|}
\hline Siniflar & Yillar & $\mathrm{CA}$ & PLAND & NP & AREA_MN & AREA_AM & IJI & MESH & PROX_AM & ENN_AM \\
\hline \multirow{2}{*}{1} & 1990 & $6.148,89$ & 27,68 & 130,00 & 47,30 & $1.519,03$ & 78,64 & 420,52 & $5.510,29$ & 90,14 \\
\hline & 2019 & $8.918,46$ & 40,16 & 209,00 & 42,67 & $2.309,89$ & 88,88 & 927,73 & $10.476,97$ & 101,00 \\
\hline \multirow{2}{*}{2} & 1990 & $1.421,28$ & 6,39 & 323,00 & 4,40 & 40,59 & 79,72 & 2,60 & 14,61 & 82,45 \\
\hline & 2019 & $1.151,46$ & 5,19 & 395,00 & 2,92 & 22,76 & 83,65 & 1,18 & 32,76 & 74,35 \\
\hline \multirow[t]{2}{*}{3} & 1990 & $2.718,90$ & 12,24 & 234,00 & 11,62 & 280,87 & 60,81 & 34,38 & 57,19 & 71,32 \\
\hline & 2019 & $2.068,74$ & 9,32 & 254,00 & 8,14 & 121,28 & 75,06 & 11,30 & 157,69 & 76,19 \\
\hline \multirow{2}{*}{4} & 1990 & $3.296,07$ & 14,83 & 350,00 & 9,42 & 230,38 & 67,11 & 34,19 & 42,02 & 109,44 \\
\hline & 2019 & $3.290,04$ & 14,82 & 376,00 & 8,75 & 120,05 & 73,97 & 17,79 & 157,08 & 111,33 \\
\hline \multirow{2}{*}{5} & 1990 & $6.339,87$ & 28,54 & 422,00 & 15,02 & 651,24 & 83,15 & 185,89 & $1.566,69$ & $1.770,00$ \\
\hline & 2019 & $4.321,26$ & 19,46 & 508,00 & 8,51 & 447,43 & 77,79 & 87,07 & 246,13 & 148,20 \\
\hline \multirow{2}{*}{6} & 1990 & $1.930,32$ & 8,69 & 2,00 & 965,16 & $1.891,48$ & 88,57 & 164,38 & 0,12 & 64,13 \\
\hline & 2019 & $1.875,96$ & 8,45 & 16,00 & 117,25 & $1.818,84$ & 72,52 & 153,66 & 0,01 & 233,83 \\
\hline \multirow{2}{*}{7} & 1990 & 356,13 & 1,60 & 152,00 & 2,34 & 16,17 & 49,59 & 0,03 & 5,04 & 157,54 \\
\hline & 2019 & 579,42 & 2,61 & 430,00 & 1,35 & 6,74 & 55,62 & 0,01 & 7,70 & 61,92 \\
\hline
\end{tabular}

Yapay yüzeylerin toplam alanında artış meydana gelmesine rağmen, NP değerinde \%12,48 artış ve AREA_AM değerinde 1,2 kat artış meydana gelmiştir. Bu durum yapay yüzeylerinin bağlantılı yamalarının alanlarının arttığını ve alan genelinde yeni yamaların oluştuğu anlamına gelmektedir. $\mathrm{Bu}$ bulgular AREA_AM, ENN_AM, PROX_AM, MESH, IJI değerleri ile desteklenmektedir (Tablo 3). Tüm bu bulgular birlikte değerlendirildiğinde ise orman alanlarında yaşanan parçalanma ve izolasyon süreçlerinin yoğunlaştığı görülmektedir. Yıllar içinde orman alanları, maki alanları, tarım alanları ve bitki örtüsü az/hiç olmayan alanlar sınıfları kentleşmenin baskısı ile yapay yüzeylere dönüşmüşlerdir.

\section{Sonuçlar ve Öneriler}

İzmir ilinin kent merkezini konu alan çalışmada, 06/07/1990 tarihine ait Landsat 4-5 TM uydu görüntüsü ve 06/07/2019 tarihine ait Landsat 8 uydu görüntüsü Nesne Tabanlı Sınıflandırma yöntemi ile sınıflandırılıp AK/AÖ haritaları elde edilmiştir. AK/AÖ haritalarının doğruluk analizleri gerçekleştirilmiştir. AK/AÖ haritaları 1990 yılında yapay yüzeyler 6148,08 ha, tarım alanları 1420,02 ha, orman alanları 2709,90 ha, maki ve otsu bitkiler 3292,38 ha, bitki örtüsü az/hiç olmayan alanlar 6336,81 ha, su yüzeyleri 1930,14 ha ve kent içi yeşil alanlar 356,13 ha; 2019 yılında ise 8915,49 ha, tarım alanları 11501,1 ha, orman alanları 20663,1 ha, maki ve otsu bitkiler 32888,7 ha, bitki örtüsü az/hiç olmayan alanlar 43202,7 ha, su yüzeyleri 18736,2 ha ve kent içi yeşil 
Karaali, İ., Ersoy Tonyaloğlu, E., Kesgin Atak, B., Nurlu, E., Uluslararası Doğu Anadolu Fen Mühendislik ve Tasarım Dergisi / International Journal of Eastern Anatolia Science Engineering and Design (IJEASED) (2020) 2(2):308-324

alanlar 5787,9 ha olarak bulunmuştur. 1990-2019 yılları arasındaki AK/AÖ değişimine bakıldığında, alanlarda sırasıyla; bitki örtüsü az/hiç olmayan alanlarında 2.016,54 ha, orman alanları 643,59 ha, tarım alanlarında 269,91 ha, su yüzeylerinde 56,52 ha, maki alanlarında 3,51 ha kayılar görülmüş̧ür. Aynı dönemde yapay yüzeyler 2.767,41 ha, kent içi yeşil alanlar ise 222,6 ha artmıştır.

Yapay yüzeylerin toplam alanında artış meydana gelmesine rağmen, NP değerinde \%12,48 artış ve AREA_AM değerinde 1,2 kat artış meydana gelmiştir. Bu durum yapay yüzeylerinin bağlantılı yamalarının alanlarının arttığını ve alan genelinde yeni yamaların oluştuğu anlamına gelmektedir. Bu bulgular, AREA_AM, ENN_AM, PROX_AM, MESH, IJI değerleri ve diğer peyzaj metrikleri ile desteklenmektedir. Tüm bu bulgular birlikte değerlendirildiğinde ise orman alanlarında yaşanan parçalanma ve izolasyon süreçlerinin yoğunlaştığı görülmektedir. Yıllar içinde orman alanları, maki alanları, tarım alanları ve bitki örtüsü az/hiç olmayan alanlar sınıfları kentleşmenin baskısı ile yapay yüzeylere dönüşmüşlerdir.

1990 ve 2019 yılları arasında yapay yüzeyler gözle görülebilecek ölçüde değişime uğramıştır. Sanayi faaliyetleri, eğitim, göç gibi nedenlerden dolayı nüfusun artmasıyla kentsel bölgelerde de artış olmuştur. Orman alanlarının bazı bölgelerde tarım alanları veya az/hiç bitki örtülü alanlara dönüştügü gözlemlense de çalışma alanı genelinde bütün sınıflardan, baskın sınıf olan yapay yüzeylere dönüşüm gerçekleşmiştir. Orman alanları, maki alanları ve tarım alanlarında yaşanan kayıpların yanı sıra bu alanlarda parçalanma ve delinme de söz konusudur. Doğal alanların giderek azalması ve kentsel bölgelerin gelişmesi ekolojik dengeyi etkilemektedir.

Bu çalışmada, 1990 ve 2019 yılları arasında meydana gelen en büyük değişim yapay yüzeyler sınıfında meydana gelmiştir. Yapay yüzeylerde baskın olarak sanayi ve yerleşim alanlarının hızla artması, doğal peyzajın bütünlüğünü bozarak peyzajda parçalanmalara, delinmelere ve izolasyona neden olmaktadır. Doğal peyzajın parçalanıp, mekansal bağlantının azalması insanlardan çok kentlerde ve kent çeperinde yaşayan birçok canlı türünü etkilemektedir. Birçok canlı türüne ev sahipliği yapan ve parçalanıp bağlantısı kopan doğal alanların, yeniden bağlantılı hale getirilmesi gerekmektedir.

Sürdürülebilir çevre ve sürdürülebilir kalkınma doğrultusunda, doğal peyzajda bozulmaları önlemek ve zararları en aza indirebilmek için doğaya uyumlu çözümler aranmalıdır. İleriye yönelik yapılan plan ve kararlarda, kentsel gelişme alanlarının doğal yapıya verilecek zararın en aza indirgenmesi ve bozulmaya uğramış doğal alanların onarılmasına ilişkin kararlara yer verilmelidir. Doğal ve kültürel peyzajların korunması, yönetilmesi ve planlanmasının önemi ve gerekliliği, doğal alanların bozulmaya uğraması, orman ve tarım alanlarının parçalanması gibi peyzaj tahribatları 
sonucu oluşan peyzajdaki parçalanmalar ve kayıplar meydana gelmesi ile anlaşılmaktadır. Çalışmada ortaya çıkarılan bilgiler doğrultusunda kentsel peyzajlardaki gelişimin doğal peyzajlara zarar vermeden, ekolojik dengeler 1şığında gerçekleşmesi sağlanmış olur.

\section{Kaynaklar}

Aguilera, F., Valenzuela, L. M. and Botequilha-Leitão, A., (2011). Landscape metrics in the analysis of urban land use patterns: A case study in a Spanish metropolitan area. Landscape and Urban Planning, 99 (3-4), 226- 238.

Alphan, H., (2003). Land- use change and urbanization of Adana, Turkey. Land Degrad. Dev., 14, 575-586.

ASTER, Global DEM Missions, (2016). https://asterweb.jpl.nasa.gov/mission.asp, (Erişim Tarihi: 1 Haziran 2020).

Atak, Kesgin, B., (2020). Analyzing Urban Landscape Structure Changes Using Landscape Metrics; The Case of Izmir. Ege Üniv. Ziraat Fak. Derg., 57 (1), 119-128.

Barredo, J. I., Kasanko, M., Mccormick, N. and Lavalle, C., (2003-b). Modelling Dynamic Spatial Processes: Simulation of Urban Future Scenarios Through Cellular Automata, Landscape and Urban Planning, 64 (3), 145-160.

Barredo, J. I., Lavalle, C., Demichel, L., Kasanko, M. and Mccormik, N., (2003-a). Sustainable Urban and Regional Planning: The MOLAND Activities on Urban Scenario Modeling and Forecast, EC Joint Research Centre Institute for Environment and Sustainability, 54.

Botequilha Leitão, A., Miller, J., Ahern, J. and McGarigal, K. (Eds.)., (2006). Measuring Landscapes: A Professional Planner's Manual, Washington, D.C.: Island Press.

Bürgi, M., Hersperger, A. M. and Schneeberger, N., (2004). Driving Forces of Landscape ChangeCurrent and New Directions, Landscape Ecology, 19 (8), 857-868.

Congalton, R. G. and Green, K., (1999). Assessing the Accuracy of Remotely Sensed Data Principles and Practices. Boca Raton: Lewis Publisher.

Deng, J. S., Wang, K., Hong, Y. and Qi, J. G., (2009). Spatio-temporal dynamics and evolution of land use change and landscape pattern in response to rapid urbanization. Landscape and Urban Planning, 92 (3-4), 187-198.

DiBari, J.N., (2007). Evaluation of five landscape-level metrics for measuring the effects of urbanization on landscape structure: the case of Tucson, Arizona, USA. Landscape and Urban Planning, 79(3-4), 308313.

Ersoy, E., (2019). Assessment of Road-Induced Landscape Fragmentation and Implications for Landscape Planning: The Case of Izmir Province, Gümüşhane Üniversitesi Fen Bilimleri Enstitüsü Dergisi, 9 (3), 699-709.

ESRI, (2019). ArcGIS 10.7 Software, Environmental Systems Research Institute, Redlands, CA.

Foody, G., (2002). Status of land cover classification accuracy assessment, Remote Sensing of Environment, $80(1), 185-201$.

Geospatial, T., (2015). eCognition Developer 9.1 Software, Trimble Navigation Limited, United States of America.

Gustafson, E. J., (1998). Quantifying Landscape Spatial Pattern: What Is the State of the Art?, Ecosystems, $1,143-156$.

Haščič I. and Mackie, A., (2018). Land Cover Change and Conversions: Methodology and Results for OECD and G20 Countries. Paris: OECD Publishing.

Herold, M., Couclelis, H., and Clarke, K.C., (2005). The role of spatial metrics in the analysis and modeling of urban land use change. Computers, environment and urban systems, 29 (4), 369-399.

Herold, M., Scepan, J. and Clarke, K., (2002). The Use of Remote Sensing and Landscape Metrics to Describe Structures and Changes in Urban Land Uses, Environment and Planning, 34(8), 1443-1458. 
Karaali, İ., Ersoy Tonyaloğlu, E., Kesgin Atak, B., Nurlu, E., Uluslararası Doğu Anadolu Fen Mühendislik ve Tasarım Dergisi / International Journal of Eastern Anatolia Science Engineering and Design (IJEASED)

(2020) 2(2):308-324

İÇDR, (2019). İzmir İli 2018 Yll Çevre Durum Raporu, Türkiye Cumhuriyeti İzmir Valiliği Çevre ve Şehircilik İl Müdürlügü. https://webdosya.csb.gov.tr/db/ced/icerikler/-zm-r 2018 -cdr son20191122120621.pdf, (Erişim Tarihi: 7 Haziran 2020).

Ji, W., Ma, J., Twibell, R. W., and Underhill, K., (2006). Characterizing urban sprawl using multi-stage remote sensing images and landscape metrics. Computers, Environment and Urban Systems, 30(6), 861-879.

Kesgin Atak, B. ve Ersoy Tonyaloğlu, E., (2019). Aydın İli Örneğinde Karbon Depolama Potansiyelinin Mekansal ve Zamansal Analizi. Afyon Kocatepe Üniversitesi Fen ve Mühendislik Bilimleri Dergisi, 19 (3), 778-786.

Kesgin, B. and Nurlu, E., (2009). Land cover changes on the coastal zone of Candarli Bay, Turkey using remote sensed data, Environmental Monitoring and Assessment, 157 (1), 89-96.

Kurtşan, K., (2018). Tarımsal Peyzaj Değissimi Analizi: İzmir ili Bornova İlçesi Örneği, Yüksek Lisans Tezi, Ege Üniversitesi Fen Bilimleri Enstitüsü, İzmir.

Leitão, A.B., Miller, J., Ahern, J. and McGarigal, K., (2012). Measuring landscapes: A planner's handbook. Island press.

L3Harris Geospatial, (2013). ENVI 5.1 Image Analysis Software, Harris Geospatial Solutions Inc., USA.

Lu, D., Mausel, P., Brondizio, E. and Moran, E., (2004). Change detection techniques, International Journal of Remote Sensing, 25 (12), 2365-2401.

Martesen, A.C., Pimentel, R.G. and Metzger, J.P., (2008). Relative effects of fragment size and connectivity on bird community in the Atlantic Rain Forest: Implications for conservation, Biological Conservation, 141(9), 2184-2192.

Matsushita, B., Xu, M. and Fukushima, T., (2006). Characterizing the changes in landscape structure in the lake Kasumigaura Basin, Japan using a high-quality GIS dataset. Landscape and Urban Planning, 78, 241-250.

McGarigal, K., Cushman, S. A. and Ene, E., (2012). FRAGSTATS v4: Spatial Pattern Analysis Program for Categorical and Continuous Maps. University of Massachusetts, Amherst. http://www.umass.edu/landeco/research/fragstats/fragstats.html, (Erişim Tarihi: 20 Mayss 2020).

McGarigal, K., (2014). FRAGSTATS help. Documentation for FRAGSTATS 4. FRAGSTATS: Spatial Pattern Analysis Program for Categorical Maps Documentation. https://www.umass.edu/landeco/research/fragstats/documents/fragstats_documents.html, Tarihi: 17 Ekim 2020).

Nurlu, E., Erdem, Ü., Güvensen, A. ve Erdoğan, N., (2009). CORINE Standartlarına Göre Karaburun Yarımadası Örneğinde Alan Kullanımı/Arazi Örtüsü Değişiminin Saptanması Üzerine Araştırma Proje Raporu, E.Ü. Bilimsel Araştırma Fonu, Proje No: 2005-ÇSUM005, İzmir.

Nurlu, E., Erdem, Ü., Öztürk, M. Güvensen, A. ve Türk, T., (2008). Landsc., Demog. Dev., Biodiversity and Sust. Land Use Strategy: A Case Study on Karaburun. Petrosillo, I., Müller, F., Jones, K.B., Zurlini, G., Krauze, K., Victorov, S., Li, B.-L., Kepner, W.G. (Eds), Use of Landsc. Scien. for the Asses. of Environ. Security (357-368). Peninsula: Springer.

OECD, (2003). OECD Environmental Indicators-Development, Measurement and Use, Reference Paper, OECD Environmental Performance and Information Division, Paris.

OECD, (2017). Green Growth Indicators 2017, Paris: OECD Publishing. http://dx.doi.org/10.1787/9789264268586, (Erişim Tarihi: 1 Haziran 2020).

Selim, S. ve Sönmez, N. K., (2015). Sığla (Liquidambar orientalis Miller) Popülasyonları Dağılımının CBS ile Belirlenmesi ve Habitat Kalitesinin Peyzaj Metrikleri Kullanılarak Değerlendirilmesi; Muğla Köyceğiz Örneği. Tekirdă̆ Ziraat Fakültesi Dergisi, 12 (1), 30-38.

Singh, A., (1989). Digital Change Detection Techniques Using Remotely-Sensed Data, International Journal of Remote Sensing, 10, 989-1003.

Somuncu, M., Akpınar, N., Kurum, E., Çabuk Kaya, N. ve Özelçi Eceral, T., (2010). Gümüşhane ili yaylalarındaki arazi kullanımı ve işlev değişiminin değerlendirilmesi: Kazıkbeli ve Alistire yaylaları örneği, Ankara Üniversitesi Çevrebilimleri Dergisi, 2(2):107-127.

Tağıl, Ş., (2014). Edremit Körfezi'nin Kuzey Sahil Bölgesinde Peyzaj Paterni ve Arazi Örtüsünün Zamansal ve Mekânsal Değişimi. Balıkesir Üniversitesi Sosyal Bilimler Enstitüsü Dergisi, 17 (31), 1-16. 
TUIK, Adrese Dayalı Nüfus Kayıt Sistemi., (2019). http://www.tuik.gov.tr/PreTablo.do?alt_id=1059, (Erişim Tarihi: 5 Haziran 2020).

Turner II, B. L., Kasperson, R. E., Meyer, W. B., Dow, K. M., Golding, D., Kasperson, J. X., Mitchell, R.C. and Ratick, S. J., (1990). Two types of global environmental change: definitional and spatial-scale issues in their human dimensions. Global Environmental Change, 1(1), 14-22.

Turner, M. G., (1989). Landscape Ecology: The Effect of Pattern on Process. Annual Review of Ecology and Systematics, 20, 171-197.

Turner, M.G., Gardner, R.H., and O’Neill. R.V., (2001). Landscape Ecology in Theory and Practice: Pattern and Process. New York, USA: Springer-Verlag.

U.S. EPA, (2008). EPA's 2008 Report on the Environment. National Center for Environmental Assessment, Environmental Protection Agency, Washington, DC, EPA/600/R07/045F.

Urban, D.L., O'Neill, R.V. and Shugart, H. H., (1987). Landscape ecology. BioScience 37:119-127.

Verburg, P. H. and Overmars, K. P., (2009). Combining Top-down and Bottom-up Dynamics in Land Use Modelling: Exploring the Future of Abandoned Farmlands in Europe with the DynaCLUE Model, Landscape Ecology, 24 (9), 1167-1181.

Yu, X. J. and Nakagoshi, C. N., (2007). Spatial and temporal dynamics of urban sprawl along two urbanrural transects: a case study of Guangzhou, China. Landscape and Urban Planning, 79, 69-109. 